\title{
OS GÊNEROS Lejeunea E Microlejeunea (LEJEUNEACEAE) NA ESTAÇÃO CIENTÍFICA FERREIRA PENNA, ESTADO DO PARÁ, BRASIL, E NOVAS OCORRÊNCIAS.
}

\author{
Anna Luiza ILKIU-BORGES ${ }^{1}$, Regina C. L. LISBOA ${ }^{1}$
}

\begin{abstract}
RESUMO - Em um inventário de Lejeuneaceae (Hepaticae) na Estação Científica Ferreira Penna, município de Melgaço, Pará, foi observada a ocorrência de Lejeunea caespitosa Lindenb. ex Gottsche, Lindenb. \& Nees, Lejeunea flava (Swartz) Nees, Lejeunea tapajosensis Spruce, Microlejeunea acutifolia Stephani e Microlejeunea epiphylla Bischler, destacando Microlejeunea acutifolia como nova ocorrência para o Brasil e Microlejeunea epiphylla mencionada pela primeira vez para o Estado do Pará. Todas as espécies estão descritas e ilustradas e é apresentada uma chave artificial para a separação das mesmas, assim como comentários adicionais.
\end{abstract}

Palavras-chave: brioflora, Lejeuneaceae, hepáticas, fitogeografia, Pará.

The Genera Lejeunea and Microlejeunea (Lejeuneaceae) in the Scientific Station Ferreira Pena, State of Pará, Brazil, and New Occurences.

ABSTRACT - A survey of the Lejeuneaceae (Hepaticae) was performed at Ferreira Penna Research Station, Melgaço municipality, Pará, where were observed Lejeunea caespitosa Lindenb. ex Gottsche, Lindenb. \& Nees, Lejeunea flava (Swartz) Nees, Lejeunea tapajosensis Spruce, Microlejeunea acutifolia Stephani and Microlejeunea epiphylla Bischler. Microlejeunea acutifolia is a new record to Brazil and Microlejeunea epiphylla Bischler is mentioned for the first time to Pará State. The species are described and illustrated and an artificial key is presented to separate them, as well as additional commentaries.

Key-words: bryoflora; Lejeuneaceae; liverworts; phytogeography; Pará.

\section{Introdução}

Dando continuidade ao inventário das espécies de Lejeuneaceae que ocorrem na Estação Científica Ferreira Penna, município de Melgaço, Pará, foram estudados os gêneros Lejeunea Libert $\mathrm{e}$ Microlejeunea Steph., ambos pertencentes à subfamília Lejeuneoideae Massal. e à tribo Lejeuneae Schuster.

O gênero Lejeunea é pantropical. Foi descrito por Libert em 1820 (Bonner \& Miller, 1960; Bischler \& Lamy, 1978) e a partir desta publicação muitas espécies foram descritas neste gênero, sendo posteriomente transferidas para outros gêneros. É um gênero de difícil identificação, do qual foram extraídas muitas espécies. Não há, ainda, uma revisão atualizada desse gênero, o que está sendo executado por ReinerDrehwald (comunicação pessoal, 1998).

O gênero Microlejeunea é pantropical e foi um dos vários gêneros que derivaram de Lejeunea, encontrando-se estreitamente relacionado a este último. Bischler et al. (1963), definem o gênero Microlejeunea com um número relativamente alto de características, das quais todas podem ser variáveis, mas que, em combinação, permitem a distinção entre as espécies. $\mathrm{O}$ estudo realizado por Bischler et al. (1963) com o gênero Microlejeunea inclui descrições, comentários e discussões sobre 14 espécies, das quais 12 estão ilustradas.

\footnotetext{
${ }^{1}$ Museu Paraense Emílio Goeldi - Dept ${ }^{\circ}$ de Botânica. C.P. 399, CEP 66040-170, Belém - PA.
} 
O objetivo deste trabalho é ampliar a distribuição geográfica de espécies dos gêneros Lejeunea e Microlejeunea e contribuir para o conhecimento da família Lejeuneaceae na Estação Científica Ferreira Penna, assim como no estado do Pará.

\section{Material e Métodos}

O material estudado é proveniente de coletas realizadas na Estação Científica Ferreira Penna (ECFPn), localizada na Floresta Nacional de Caxiuanã, município de Melgaço, estado do Pará, Brasil.

A coleta do material seguiu o método adotado por Yano (1984a) e Lisboa (1993).

As espécies foram classificadas de acordo com o tipo de substrato onde foram coletadas, segundo Robbins (1952).

A identificação taxonômica foi feita através de chaves de identificação em bibliografia especializada e/ou comparação com espécies identificadas por especialistas.

O material estudado encontra-se depositado no Herbário "João Murça Pires" (MG), do Museu Paraense Emílio Goeldi.

\section{Resultados e Discussões}

As espécies do gênero Lejeunea caracterizam-se pela presença de lóbulos com papila hialina proximal, ausência de ocelos ou pigmentação acastanhada nas paredes celulares e periantos com inovações do tipo lejeuneóide de acordo com ReinerDrehwald (comunicação pessoal,
1998). Entretanto essas características podem ser observadas também em Microlejeunea, mas este último agrupa apenas espécies muitos pequenas, com caulídio em zig-zag.

Foram identificadas três espécies de Lejeunea e duas de Microlejeunea para a área da Estação Científica Ferreira Penna, apresentadas a seguir.

\section{Lejeunea Libert}

1. Filídios caducos presentes; anfigastros com 200-300mm de comprimento e 200$350 \mathrm{~mm}$ de largura L. tapajosensis

1'. Filídios caducos ausentes; anfigastros menores. 2

2. Gametófitos pequenos com 0,35 $0,4 \mathrm{~mm}$ de largura; anfigastros

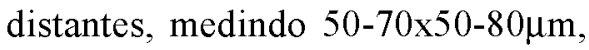
base acuneada a levemente arredondada L. caespitosa 2'. Gametófitos maiores com 0,7$0,8 \mathrm{~mm}$ de largura; anfigastros geralmente contíguos, sub-ovalados e romboidais, medindo 160-200x170$200 \mu \mathrm{m}$, base reta a levemente auriculada L. flava

Lejeunea caespitosa Lindenb. ex Gottsche, Lindenb. \& Nees in G. L. \& N., Syn. Hep., p. 382.1845

(Fig. 1).

Tipo: África do Sul. Cape of Good Hope, hb. Hooker 18.

Gametófitos verde-claros a pálidos, pequenos, prostrados, 5$10 \mathrm{~mm}$ de comprimento e $0,35-0,4 \mathrm{~mm}$ de largura. Caulídio em secção transversal com 5-7 células epidérmicas circundando 4 células medulares menores, merófito ventral de 2 células 

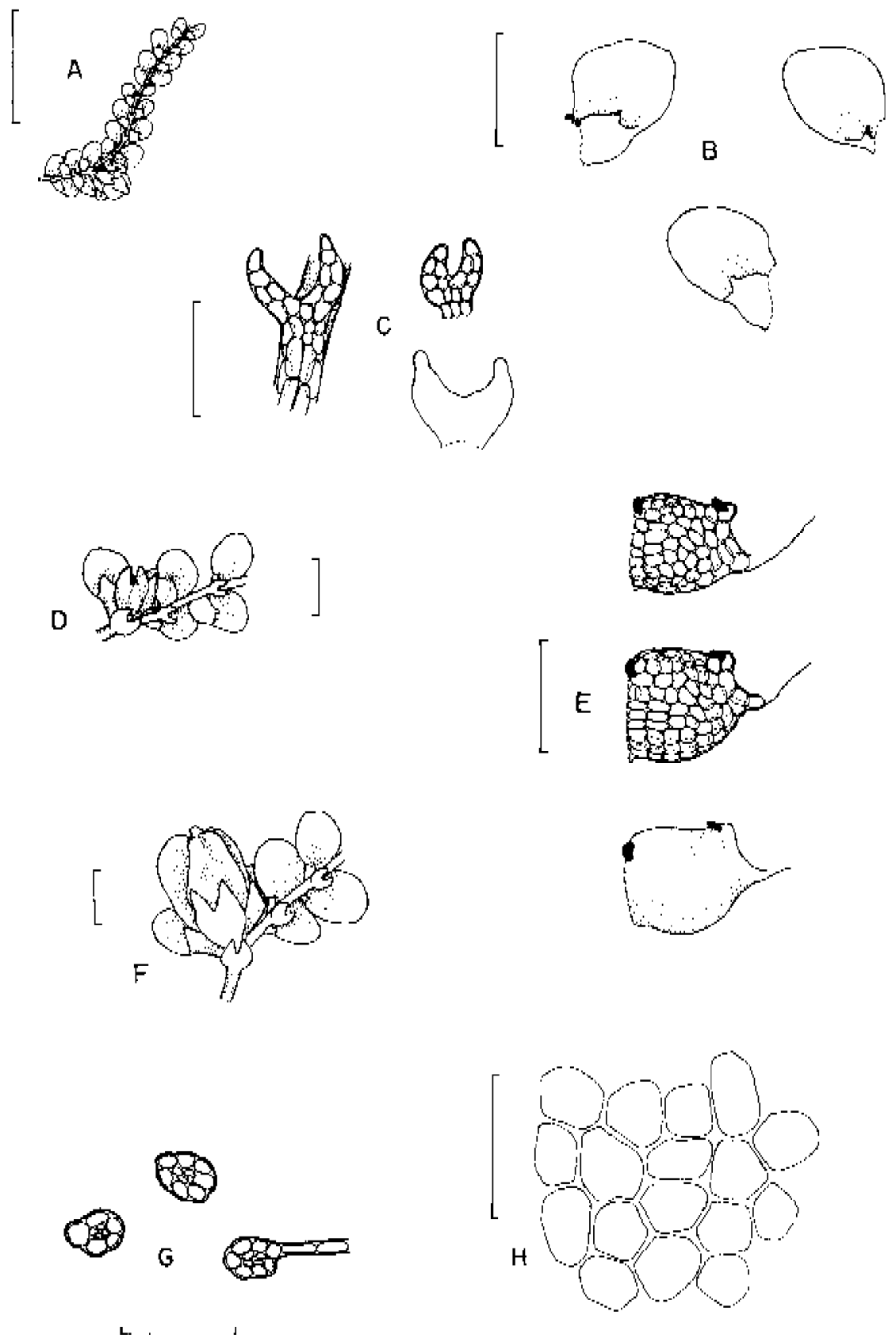

Figura 1. Lejeunea caespitosa $(\mathrm{A}-\mathrm{H}) \mathrm{A}$. hábito, vista ventral; B. filídios; C. anfigastros; D. gineceu com inovação; E. lóbulos com papilas hialinas destacadas; F. perianto; G. secções transversais do caulídio; H. células da região mediana do filídio (R. Lisboa, A. L. Ilkiu-Borges $\&$ M. Silva, 6123); Escalas: $A=1 \mathrm{~mm} ; \mathrm{B}, \mathrm{D}$ e $\mathrm{F}=200 \mu \mathrm{m}$; $\mathrm{C}, \mathrm{E}$ e $\mathrm{G}=100 \mu \mathrm{m} ; \mathrm{H}=50 \mu \mathrm{m}$ (Desenho: Anna Luiza Ilkiu-Borges). 
de largura. Filídios elíptico-ovalados, geralmente sub-imbricados, $210 \mu \mathrm{m}$ de comprimento e 170-200 $\mu \mathrm{m}$ de largura, ápice arredondado, margens inteiras, células isodiamétrica-poligonais, 15$20 \mu \mathrm{m}$ de diâmetro, trigônios inconspícuos. Lóbulos ovalados, inflados, $100 \mu \mathrm{m}$ de comprimento e $90 \mu \mathrm{m}$ de largura, margem livre mais ou menos plana próximo ao ápice, dente apical unicelular, curto, obtuso a arredondado, papila hialina na base proximal do dente apical. Anfigastros distantes, bífidos até a metade do comprimento, raramente mais, 50 $70 \mu \mathrm{m}$ de comprimento e $50-80 \mu \mathrm{m}$ de largura, lobos eretos, apiculados, terminando em 1-2 células enfileiradas, separados por um sinus em forma de "V" largo, às vezes mais agudo, base reta a arredondada. Androceu não observado. Gineceu no ramo principal, com 1 inovação do tipo lejeuneóide, brácteas obovadas, ápice obtuso, lóbulos lanceolados, bractéola grande, bem maior que um anfigastro, bífida, obovada, cobrindo $1 / 2$ perianto ou um pouco mais. Periantos obovados, com 5 quilhas, achatadas, $430 \mu \mathrm{m}$ de comprimento e $280 \mu \mathrm{m}$ de largura, rostro conspícuo. Esporófito não observado.

Distribuição geográfica: Ocorre nos Estados Unidos, Costa Rica, Cuba, Porto Rico, Peru, Guiana Francesa e alguns países da África (Lücking, 1995). No Brasil ocorre nos estados do AC, PA, RJ e SP (Vital \& Visnadi, 1994; Lisboa \& Ilkiu-Borges, 1995; Visnadi, 1998; Silva, 1998).

Discussão: Esta é uma espécie corticícola, em ecossistema de várzea na ECFPn. Apresenta gametófitos pequenos, prostrados e verde claros. Nos filídios os lobos são sempre duas vezes maiores que os lóbulos ovalados, inflados, com um dente unicelular obtuso, porém as vezes os lóbulos podem estar reduzidos. Além disso, apresenta anfigastros delicados, bífidos, com lobos apiculados, separados por um sinus em forma de "V" largo e formado por células com paredes delgadas.

Material examinado: Melgaço (PA), ECFPn: margem esquerda do rio Curuá, várzea, sobre estipe de açaizeiro (Euterpe oleracea Mart.), 8.XII.1997, A. L. Ilkiu-Borges, O. Nascimento \& M. Silva, 1067; idem, sobre cipó, 8.XII.1997, A. L. IlkiuBorges, O. Nascimento \& M. Silva, 1081; próximo à baía de Caxiuanã, várzea, ao redor da vegetação savanóide, sobre estipe de açaizeiro (Euterpe oleracea Mart.), 4.XI.1996, R. Lisboa, A. L. Ilkiu-Borges \& M. Silva, 6123.

\section{Lejeunea flava (Swartz) Nees in}

Natrg. Europ. Leberm. 3: 277. 1838

(Fig. 2).

Basiônimo: Jungermannia flava Swartz in Gen. Spec. Plant. Prodromus, 144. 1788.

Tipo: Jamaica. Swartz. (Lectótipo, UPS; Isótipo, BM).

Gametófitos verdes a amarelados, prostrados, $10-15 \mathrm{~mm}$ de comprimento e $0,7-0,8 \mathrm{~mm}$ de largura. Caulídio em secção transversal com 7 8 células epidérmicas circundando 911 células medulares menores, merófito ventral de 2 células de 

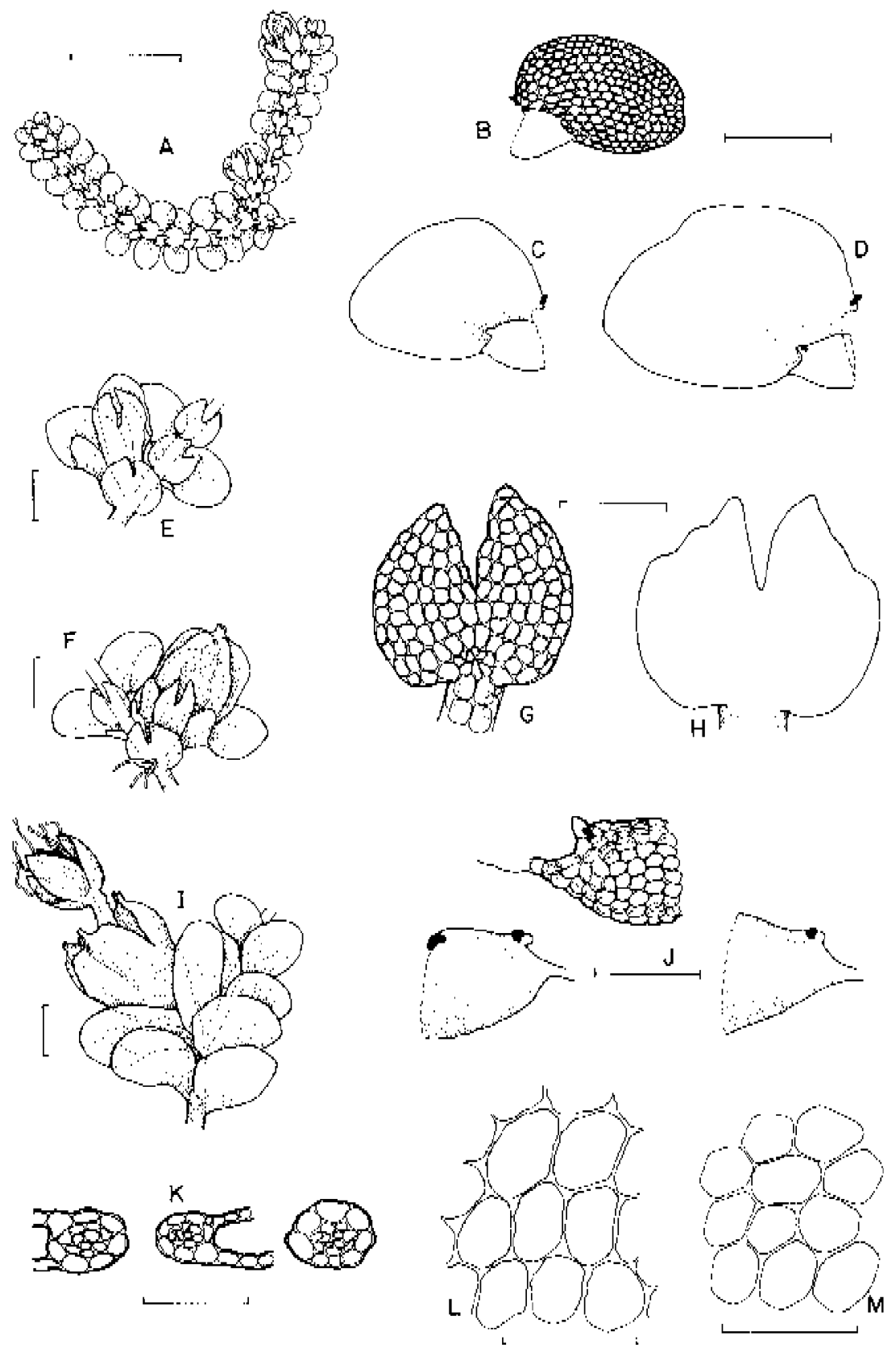

Figura 2. Lejeunea flava (A-M) A. hábito, vista ventral; B, C e D. filídios; E. gineceu com inovação; F. perianto; G e H. anfigastros; I. perianto rompido com esporófito; J. lóbulos; K. seç̧ões transversais do caulídio; L. células da região mediana do filídio com trigônios médios; M. células da região mediana do fílídio com trigônios pequenos ( R. Lisboa, A. L. Ilkiu-Borges $\&$ M. Silva, 6105); Escalas: A $=1 \mathrm{~mm} ; \mathrm{B}, \mathrm{C}, \mathrm{D}, \mathrm{E}, \mathrm{F}$ e I $=200 \mu \mathrm{m} ; \mathrm{G}, \mathrm{H}, \mathrm{J}$ e K $=100 \mu \mathrm{m}$; L e $\mathrm{M}=50 \mu \mathrm{m}$ (Desenho: Anna Luiza Ilkiu-Borges). 
largura. Filídios ovalados, subimbricados, $330-450 \mu \mathrm{m}$ de comprimento e 250-350 $\mu \mathrm{m}$ de largura, ápice arredondado, margens inteiras, células do meio do lobo isodiamétricapoligonais, com $20-35 \mu \mathrm{m}$ de diâmetro; células basais mais alongadas, com 30$40 \mu \mathrm{m} \times 20-25 \mu \mathrm{m}$, trigônios pequenos a inconpícuos. Lóbulos ovalados, inflados, $120 \mu \mathrm{m}$ de comprimento e 80 $90 \mu \mathrm{m}$ de largura, margem livre mais ou menos involuta, dente apical curto e arredondado, dirigido para o centro do lobo, quilha do lóbulo arqueada, papila hialina na base proximal do dente apical. Anfigastros sub-ovalados a romboidais, geralmente contíguos, às vezes mais ou menos distantes, bífidos até a metade do comprimento, com lobos eretos com um sinus em forma de "V", base reta a levemente auriculada, $\quad 160-200 \mu \mathrm{m}$ de comprimento e 170-220 $\mu \mathrm{m}$ de largura. Androceu não observado. Gineceu em ramos especializados, com 1 inovação do tipo lejeuneóide, brácteas obovadas, ápice obtuso, lóbulos largo-lanceolados, bractéola grande, maior que um anfigastro, bífida até $1 /$ 3 do comprimento, longo-obovada, cobrindo até a metade do perianto. Periantos oblongo-obovados, com 5 quilhas, achatadas, $530-550 \mu \mathrm{m}$ de comprimento e 300-330 $\mu \mathrm{m}$ de largura, rostro elevado e conspícuo. Esporófito não observado.

Distribuição geográfica: É uma espécie pantropical, segundo Schuster (1980). No Brasil, é mencionada para os estados do AM, ES, GO, MG, PE, RJ, RR e SP, (Yano, 1984b, 1995), e ainda para o AC (Vital \& Visnadi,
1994), PA (Lisboa \& Ilkiu-Borges, 1995) e BA (Harley, citado por Visnadi, 1998).

Discussão: É uma espécie bastante comum, com ampla adaptação ecológica. Schuster (1980) afirma que esta espécie pode ser corticícola, saxícola ou epífita. Além disso, é uma espécie que apresenta variações morfológicas em diversos caracteres (Reiner-Drehwald, comunicação pessoal, 1998). Distingue-se pela presença de lobos, lóbulos ovalados, inflados, com a margem livre mais ou menos involuta e um dente apical curto e arredondado, dirigido para o centro do lobo e quilha arqueada e anfigastros geralmente contíguos, sub-ovalados e ronboidais, bífidos, com lobos eretos com um sinus em "V", base reta a levemente auriculada.

Material examinado: Melgaço (PA), ECFPn: igarapé Laranjal, caminho para o laranjal, mata de capoeira, sobre folha de palmeira, 7.XII.1997, A. L. Ilkiu-Borges, 1007; próximo à baía de Caxiuanã, várzea, ao redor da vegetação savanóide, sobre estipe de palmeira (mucajá), 4.XI.1996, R. Lisboa, A. L. IlkiuBorges \& M. Silva, 6105.

\section{Lejeunea tapajosensis Spruce in}

Trans. \& Proc. Soc. Bot. Edinburgh, 15: 223. 1888 (Fig. 3).

Tipo: Brasil. "Ad fluminum Amazonum et Tapajos confluentiam, ..." (Holótipo: Spruce L 251, MANCH18328)

Gametófitos verde-pálidos, prostrados, muito frágeis, 


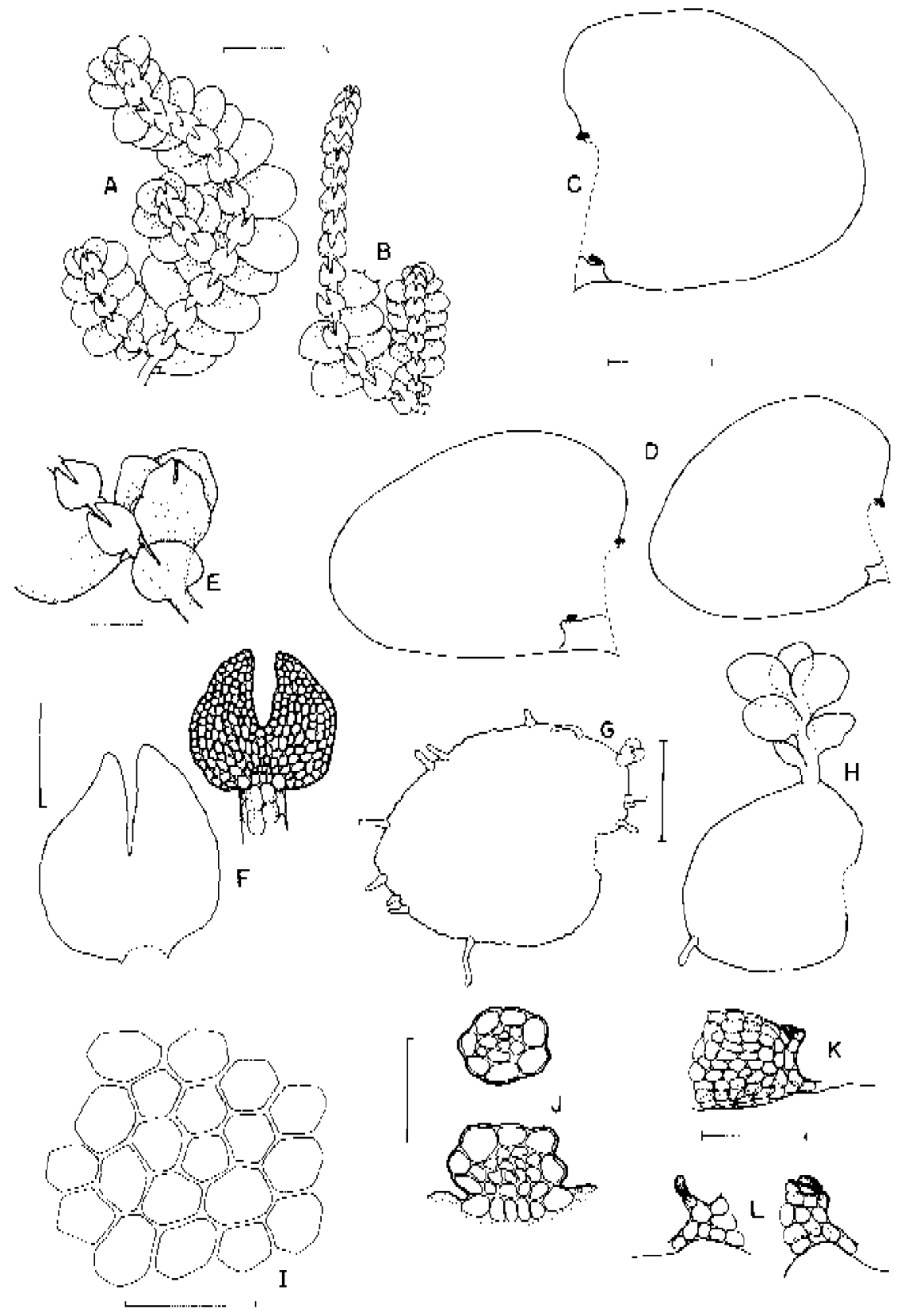

Figura 3. Lejeunea tapajosensis (A-L) A. hábito, vista ventral; B. hábito com ramos de filídios caducos, vista ventral; C e D. filídios; E. gineceu com inovação; F. anfigastros; G. filídio caduco; H. fillídio caduco com cládia marginal; I. células da região mediana do fillídio; J. secções transversais do caulídio; $\mathrm{K}$. lóbulo desenvolvido; L. lóbulos reduzidos (R. Lisboa, A. L. IlkiuBorges \& M. Silva, 6078); Escalas: A e B $=1 \mathrm{~mm}$; C, D, E, F, G e H $=200 \mu \mathrm{m} ; \mathrm{J}, \mathrm{K}$ e L = $100 \mu \mathrm{m} ; \mathrm{I}=50 \mu \mathrm{m}$ (Desenho: Anna Luiza Ilkiu-Borges). 
frouxamente aderidos ao substrato, 5$15 \mathrm{~mm}$ de comprimento e $0,8-1,1 \mathrm{~mm}$ de largura, geralmente com ramos sem filídios (filídios caducos), apenas com anfigástrios. Caulídio em secção transversal com 7-10 células epidérmicas circundando 8-15 células medulares menores, merófito ventral de 2 células de largura. Filídios ovalados a elíptico-ovalados, planos, imbricados, $400-600 \mu \mathrm{m}$ de comprimento e 350-500 $\mu \mathrm{m}$ de largura, ápice obtuso a arredondado, margens inteiras, às vezes irregularmente crenuladas por células projetadas; células do meio do lobo isodiamétricapoligonais, $17-20 \mu \mathrm{m}$, trigônios pequenos a inconspícuos. Lóbulos, quando desenvolvidos, ovalados, inflados, $100-110 \mu \mathrm{m}$ de comprimento e $70-80 \mu \mathrm{m}$ de largura, quilha do lóbulo levemente arqueada, margem livre mais ou menos involuta na base, mais plana no ápice, dente apical obtuso, formado por uma célula pequena, papila hialina na base proximal do dente apical em um breve sinus lunulado, os lóbulos podem estar reduzidos, neste caso, são trapezoidais, quilha mais ou menos convexa, dente apical formado por uma célula arredondada com a papila hialina na base proximal do dente apical, às vezes pode estar apontada para o ápice. Anfigastros distantes a subimbricados largo-ovalados, margens inteiras, bífidos até $1 / 2$ do comprimento ou um pouco mais, lobos eretos, ponteado-arredondados, separados por um sinus agudo, base reta a levemente acuneada, linha de inserção mais ou menos curvada, 200$300 \mu \mathrm{m}$ de comprimento e $200-350 \mu \mathrm{m}$ de largura, anfigastros dos ramos com filídios caducos, às vezes com margens laterais mais ou menos angulosas, subimbricados a imbricados. Reprodução vegetativa por meio de filídios caducos, do mesmo tamanho ou um pouco menores que os filídios normais, com vários rizóides marginais, às vezes com ramos flageliformes marginais. Androceu não observado. Gineceu em ramos alongados, com 1 inovação do tipo lejeuneóide, brácteas longo-obovadas, ápice obtuso, lóbulos largolanceolados com ápice arredondado, bractéola grande, longo-obovada, maior que um anfigastro, bífida até mais ou menos $1 / 4$ do comprimento, sinus agudo. Perianto e esporófito não observados.

Distribuição geográfica: Esta espécie ocorre no Brasil, onde é citada para o estado do ES, PA, PE (Spruce, 1885; Yano, 1995).

Discussão: L. tapajosensis apresenta grandes anfigastros e filídios caducos e reprodução vegetativa por meio de filídios caducos que se desprendem do caulídio sem os lóbulos. Na ECFPn, essa é uma espécie corticícola, coletada em vegetação savanóide, local bastante exposto ao sol.

Material examinado: Melgaço (PA), ECFPn: baía de Caxiuanã, área de vegetação savanóide, periodicamente inundada, sobre árvore viva, 4.XI.1996, R. Lisboa, A. L. IlkiuBorges \& M. Silva, 6078.

\section{Microlelejeunea Stephani}

1. Filídios ovalados, ápice agudo; anfigastros profundamente bífidos 
com lobos filiformes, formados por 3 células enfileiradas, sem lâmina, com apenas duas células na linha de inserção M. acutifolia

1'. Filídios oblongos, ápice arredondado a arredondado-sinuoso; anfigastros ovalados com lobos formados por 2 células enfileiradas e lâmina formada por 8-9 células M. epiphylla

\section{Microlejeunea acutifolia Stephani,} in Hedwigia, 35: 113. 1896 (Fig. 4, A-K).

Tipo: Trinidad. S. loc., 1912, Crüger s. n. (Holótipo, G).

Gametófitos verde-claros, muito pequenos, delicados, prostrados, $2 \mathrm{~mm}$ de comprimento e $0,23 \mathrm{~mm}$ de largura. Caulídio em secção transversal com 67 células epidérmicas circundando 3 células medulares menores, merófito ventral de 2 células de largura. Filídios ovalados, raramente reduzidos, o lobo se estreita após o lóbulo, ápice agudo, às vezes agudo-arredondado, dispostos formando um ângulo de $25^{\circ} \mathrm{com} o$ caulídio, distantes, 150-170 $\mu \mathrm{m}$ de comprimento e $80-90 \mu \mathrm{m}$ de largura, margens inteiras a levemente crenuladas por causa do contorno das células; células do lobo isodiamétricapoligonais, $10-13 \mu \mathrm{m}$, trigônios inconspícuos, paredes celulares delgadas. Lóbulos ovalados, inflados na base, $100-120 \mu \mathrm{m}$ de comprimento e $80-90 \mu \mathrm{m}$ de largura, quilha do lóbulo fortemente arqueada, margem livre involuta na base e mais ou menos plana próximo ao ápice, dente apical arredondado, formado por 1 célula levemente alongada, papila hialina na base proximal do dente apical, no ápice do lóbulo forma-se uma boca convexa a lunulada, lóbulos raramente reduzidos a $1 / 3$ do comprimento dos filídios, neste caso com um dente apical mais destacado, com uma papila proximal, direcionada para o ápice. Anfigastros compridos, distantes, profundamente bífidos, lobos filiformes, formado por 3 células enfileiradas, divergentes, formando sinus em forma de "V", ou divergentes na base e convergentes no ápice, sem lâmina, apenas uma base estreita, formada por 2 células, $50-60 \mu \mathrm{m}$ de comprimento e $20 \mu \mathrm{m}$ de largura, margens inteiras, linha de inserção reta. Androceu, gineceu, perianto e esporófito não observados.

Distribuição geográfica: É mencionada para a Colômbia, Costa Rica, El Salvador, Guadaloupe, Guiana, Guiana Francesa, Kokosinsel, Martinica, México, Porto Rico, St. Vicent, Suriname e Trinidad (Bischler et al., 1963; Lücking, 1995). Neste trabalho é citada pela primeira vez para o Brasil.

Discussão: Segundo Bischler et al. (1963), esta é uma espécie das Antilhas, que também ocorre na Guiana Francesa, onde é bastante comum. De acordo com os mesmos autores, $M$. acutifolia pode ser epíxila ou epífila, crescendo com outras briófitas. Na ECFPn, essa espécie ocorreu sobre tronco, misturada a outras três espécies de Lejeuneaceae (Ceratolejeunea sp., Pictolejeunea picta (Gott. ex Steph.) Grolle e Trachylejeunea sp.). 

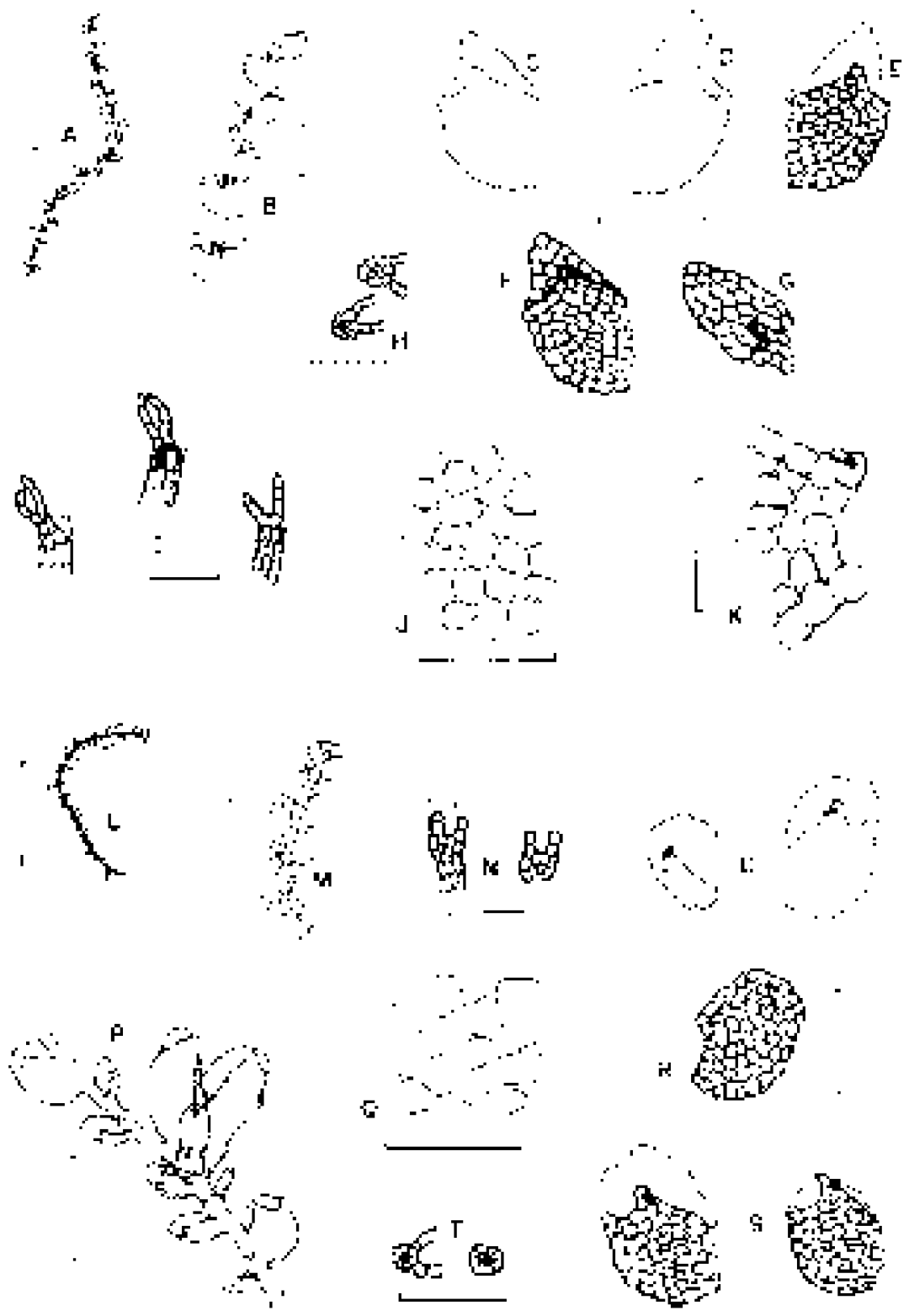

Figura 4. Microlejeunea acutifolia (A-K) A. hábito, vista ventral; B. hábito em detalhe; C, D, E e F. filídios com lóbulos desenvolvidos; G. filídio com lóbulo reduzido; $\mathrm{H}$. secções transversais do caulídio; I. anfigastros; J. células da região mediana do filídio; $\mathrm{K}$. detalhe interno do ápice do lóbulo, destacando papila hialina (A. L. Ilkiu-Borges, O. Nascimento \& M. Silva, 1010); Microlejeunea epiphylla (L-T) L. hábito, vista ventral; M. hábito em detalhe; N. anfigastros; O. filídios; P. gineceu com inovação; Q. células da região mediana do filídio; $R$. fílídio, vista dorsal; S. filídios com lóbulos em destaque; T. secções transversais do caulídio (A. L. IlkiuBorges, R. Lisboa \& M. Silva, 702); Escalas: A e L = 1mm; B, M e P = 200 $\mu \mathrm{m}$; C, D, E, F, G, $\mathrm{H}, \mathrm{I}, \mathrm{N}, \mathrm{O}, \mathrm{R}, \mathrm{S}$ e $\mathrm{T}=100 \mu \mathrm{m} ; \mathrm{J}, \mathrm{K}$ e $\mathrm{Q}=50 \mu \mathrm{m}$ (Desenho: Anna Luiza Ilkiu-Borges). 
Material examinado: Melgaço (PA), ECFPn: igarapé Laranjal, caminho para o laranjal, mata de capoeira, sobre tronco de abiu casca-solta, 7.XII.1997, A. L. Ilkiu-Borges, 1010.

\section{Microlejeunea epiphylla Bischler in}

Bischler, Miller \& Bonner, Nova Hedwigia, 5: 378. 1963 (Fig. 4, L-T).

Tipo: Guadaloupe. La soufrière, 1467m., 24.VII.1954, Le Gallo, s. n (Holótipo, PC).

Gametófitos verde-claros, muito pequenos, delicados, prostrados, $2 \mathrm{~mm}$ de comprimento e $0,21 \mathrm{~mm}$ de largura. Caulídio em secção transversal com 78 células epidérmicas circundando 34 células medulares menores, merófito ventral de 2 células de largura. Filídios oblongos, freqüentemente reduzidos, dispostos formando um ângulo de $25^{\circ}$ com o caulídio, distantes, $90-140 \mu \mathrm{m}$ de comprimento e $60-100 \mu \mathrm{m}$ de largura, ápice arredondado a arredondado-sinuoso, margens inteiras a levemente crenuladas devido ao contorno das células, células do lobo isodiamétrica-poligonais, às vezes mais ou menos alongadas, $12-20 \times 10-$ $15 \mu \mathrm{m}$, trigônios inconspícuos, paredes celulares delgadas. Lóbulos ovalados, inflados na base, $100-120 \mu \mathrm{m}$ de comprimento e $80-90 \mu \mathrm{m}$ de largura, quilha do lóbulo fortemente arqueada, margem livre involuta na base e mais ou menos plana próximo ao ápice, dente apical arredondado, formado por 1 célula levemente alongada, papila hialina na base proximal do dente apical, no ápice do lóbulo forma-se uma boca lunulada, lóbulos às vezes reduzidos em filídios menores, neste caso altera-se apenas a forma para oblongo-retangulares. Anfigastros ovalados, distantes, bífidos, lobos eretos, filiformes, formado por 2 células enfileiradas, lâmina formada por 8-9 células, $50-60 \mu \mathrm{m}$ de comprimento e $30-40 \mu \mathrm{m}$ de largura, base levemente arredondadaacuneada, margens inteiras, linha de inserção reta. Androceu não observado. Gineceu terminal no ramo principal, 0-1 inovação do tipo lejeuneóide, brácteas com lobos elípticos, ápice arredondado, lóbulos elíptico-lanceolados, do mesmo comprimento das brácteas, bractéola obovada, maior que um anfigastro e a metade o comprimento das brácteas, bífida, lobos eretos, triangulares, sinus com forma de "V". Periantos e esporófito não observados.

Distribuição geográfica: Ocorre no Brasil, Colômbia, Costa Rica, Guadaloupe, Guiana Francesa, El Salvador e Martinica, (Bischler et al., 1963; Lücking, 1995). No Brasil é mencionada para o estado de PE (Yano, 1995). Aqui é citada pela primeira vez para o estado do PA.

Discussão: Espécie epífila, de acordo com Bischler et al. (1963), conforme o próprio epíteto justifica. Diferencia-se de $M$. acutifolia, pois esta última apresenta filídios com lobo ovalado e ápice agudo e anfigastros profundamente bífidos com lobos filiformes, formados por 3 células enfileiradas, sem lâmina, com apenas duas células na linha de inserção, enquanto $M$. epiphylla apresenta filídios com lobos oblongos, com 
ápice arredondado a arredondadosinuoso e anfigástrios ovalados, com lobos formados por 2 células enfileiradas e lâmina formada por 8-9 células.

Material examinado: Melgaço (PA), ECFPn: margem direita do igarapé Curuazinho, inventário 11, várzea, sobre folhas vivas, 5.XI.1996, A. L. Ilkiu-Borges, R. Lisboa \& M. Silva, 702 .

\section{Conclusões}

A espécie Microlejeunea epiphylla é mencionada pela primeira vez para o Estado do Pará e a espécie Microlejeunea acutifolia é uma nova ocorrência para o Brasil.

Entre as espécies de Lejeunea encontradas na Estação Científica Ferreira Penna, observa-se que os substratos utilizado foram tronco de árvore viva e folha de plantas do subbosque. L. caespitosa e $L$. tapajosensis ocorreram exclusivamente sobre troncos de árvores vivas, enquanto $L$. flava ocorreu sobre tronco vivo e sobre folha viva, o que demostra sua maior amplitude ecológica en relação às outras duas espécies.

A espécie Lejeunea caespitosa foi observada somente no ecossistema de várzea, $L$. tapajosensis somente na vegetação savanóide, enquanto $L$. flava foi coletada uma vez em ecossistema de várzea e outra em capoeira.

$\mathrm{Na}$ ECFPn as espécies de Microlejeunea são raras. Microlejeunea acutifolia foi coletada somente uma vez, sobre tronco de árvore viva e $M$. epiphylla foi coletada também apenas uma vez, neste caso sobre folha viva.

Microlejeunea epiphylla ocorreu somente no ecossistema de várzea $\mathrm{e}$ $M$. acutifolia destacou-se como a única espécie exclusiva de capoeira.

\section{Bibliografia citada}

Bischler, H. ; Bonner, C. E. B.; Miller, H. A. 1963. Studies in Lejeuneaceae VI. The genus Microlejeunea Steph. in Central and South America. Nova Hedwigia, v. 5, p. 359-423.

Bischler, H., Lamy, D. 1978. Pars IX: Jungermanniopsis to Lejeunites. In: Bonner, C. E. B. (comp.). Index Hepaticarum. Germany: J. Cramer, p. 405745.

Bonner, C. E. B., Miller, H. A. 1960. Studies en Lejeuneaceae. I. the Typication of Lejeunea. The Bryologist, v. 63, n. 4, p.217-225.

Lisboa, R.C.L. 1993. Musgos Acrocárpicos do Estado de Rondônia. Belém: Museu Paraense Emílio Goeldi. 272p.

Lisboa, R.C.L., Ilkiu-Borges, A. L. 1995. Diversidade das briófitas de Belém (PA) e seu potencial como indicadoras de poluição urbana. Bol. Mus. Par. Emílio Goeldi, sér. Bot., v. 11, n. 2, p. 199-225.

Lücking, A. 1995. Diversität und Mikrohabitatpräferenzen epiphyller Moose in einem tropichen Regenwald in Costa Rica. U1m, 1995. $211 \mathrm{p}$. Tese (Doutorado) - Universidade de Ulm.

Robbins, R. G. 1952. Bryophyta Ecology of a dune area in New Zealand. Vegetatio, Acta Geobotânica, v. 4, p. 1-31.

Schuster, R. M. 1980. The Hepaticae and Anthocerothe of North America. East of the Hundredth Meridian. New York: Columbia University Press, v. 4, 1334p.

Silva, M.I.M.N. de O. 1998. Briófitas da Reserva Ecológica de Rio das Pedras, município de Mangaratiba, do Parque Estadual da Ilha Grande e da Reserva Biologica Estadual da Praia do Sul, 
município de Angra dos Reis, estado do Rio de Janeiro. São Paulo: Universidade de São Paulo. 321p. (tese de doutorado).

Spruce, R. 1985. Hepaticae of the Amazon and the Andes of Peru and Equador. Contr. N. Y. bot. Gdn., v. 15, p. 1-588 (reimpressão).

Vital, D. M., Visnadi, S. R. 1994. Bryophytes of Rio Branco Municipality, Acre, Brasil. Tropical Bryology, v. 9, n. 69-74.

Visnadi, S. R. 1998. Briófitas em ecossistemas costeiros do Núcleo Picinguaba do Parque Estadual da Serra do Mar, Ubatuba-SP. São Paulo: Universidade Estadual Paulista. 273p. (tese de doutorado).

Yano, O. 1984a. Briófitas. In: Fidalgo, O., Bononi, V. L. R. (Coord.). Técnicas de coleta, preservação e herborização de material botânico. São Paulo: Instituto de Botância. 62p. (Manual, 4)

Yano, O. 1984b. Checklist of Brazilian Liverworts and Hornworts. J. Hattori Bot. Lab., v. 56, p. $481-548$.

Yano, O. 1995. A New Additional Checklist of Brazilian Bryophytes. J. Hattori Bot. Lab., v. 78, p. $137-182$.

Aceito para publicação em 12/03/2002 
